\title{
COMPARISON OF DEXMEDITOMIDINE AND PROPOFOL FOR HEMODYNAMIC AND RECOVERY CHARACTERISTICS IN DILATATION AND CURETTAGE.
}

1. MBBS, FCPS (Anaesthesia) Assistant Professor DHQ Teaching Hospital Sargodha.

2. MBBS, FCPS (Surgery)

Associate Professor

DHQ Teaching Hospital Sargodha.

3. MBBS, FCPS (Surgery)

Associate Professor

DHQ Teaching Hospital Sargodha.

4. MBBS, FCPS (Anaesthesia)

Assistant Professor

Doctors Trust Teaching Hospital Sargodha.

5. MBBS, FCPS (Surgery)

Senior Registrar

DHQ Teaching Hospital Sargodha.

6. MBBS, FCPS (Surgery)

Assistant Professor

DHQ Teaching Hospital Sargodha.

Correspondence Address:

Dr. Raza Farrukh

Department of Anaesthesia

DHQ Teaching Hospital Sargodha/

Sargodha Medical College.

riz192@yahoo.com

Article received on:

07/10/2019

Accepted for publication:

08/01/2020

\section{INTRODUCTION}

Minor surgical procedures are usually performed as day care procedures in order to save the hospital resources. The most common minor surgery in obstetrics and gynecology is Dilatation and curettage ( $D \& C) .{ }^{1}$ Propofol is considered an ideal agent for day care surgeries because of rapid onset and recovery. ${ }^{2}$ The combination of sedative and analgesic is frequently used for minor surgical procedure. Propofol and opioid is the most frequently used combination for D\&C. Although propofol has the advantage of rapid recovery from anaesthesia but as it has no analgesic property so its combination with opioids can lead to respiratory depression. ${ }^{3}$

Dexmedetomidine is an alpha-2 agonist which provides analgesia, sedation and cardiovascular stability without any respiratory depression. ${ }^{4,5}$ It provides conscious sedation which leads to early recovery from anaesthesia. Dexmeditomidine also potentiates the analgesic effect of opioids so combination of dexmeditomidine with opioids such as nalbuphine seems to be a better option for minor gynecological procedures. ${ }^{6}$ This combination can also lead to early discharge from post anaesthesia recovery unit. ${ }^{7}$ There is inadequate data available for use of dexmedetomidine in $\mathrm{D} \& \mathrm{C}$.

The main aim of this research was to compare the intraoperative hemodynamic changes, respiratory effects and the recovery profile of dexmedetomidine with propofol in patients undergoing $D \& C$.

\section{MATERIAL \& METHODS}

After taking written consent from hospital ethical committee and patients, 50 patients fulfilling the inclusion criteria were enrolled in the study. Preoperative anaesthesia assessment was done. Baseline vitals such as heart rate, systolic 
blood pressure, diastolic blood pressure, mean arterial blood pressure and oxygen saturation were recorded. Intravenous line was taken in preoperative room and infusion of ringer lactate started. Standard ASA monitors were applied to all patients. Patients were randomly divided into two groups, Group $P$ received propofol and Group D received dexmeditomodine. Patients in both groups were given injection nalbuphine $0.1 \mathrm{mg} / \mathrm{kg}$ and injection midazolam $2 \mathrm{mg}$ intravenous prior to start of procedure. Oxygen was given to patients of both groups through nasal cannula at the rate of 3 liter/ min. Patients in group $P$ were given propofol $1.5 \mathrm{mg} / \mathrm{kg}$ slow intravenous bolus over 5 min. Patients in group $\mathrm{D}$ were given dexmeditomidine at loading dose of $1 \mu \mathrm{g} / \mathrm{Kg}$ intravenous over 5 min followed by $0.5 \mu \mathrm{g} / \mathrm{kg} / \mathrm{hr}$ infusion till Ramsay sedation score 3-4 achieved. Propofol was given intravenous in incremental boluses of $10 \mathrm{mg}$ in case patient was uncomfortable. During procedure heart rate and mean arterial blood pressure (MAP) were recorded at $0 \mathrm{~min}, 2 \mathrm{~min}, 4 \mathrm{~min}, 10 \mathrm{~min}$ and $15 \mathrm{~min}$ and post operatively in recovery room .Decrease in Oxygen saturation less than $90 \%$ were also noted in both groups and treated accordingly. After completion of procedure, all patients were shifted to anaesthesia recovery area. Postanaesthesia recovery was assessed by modified Aldrete scoring system every 5 minutes. All patients were discharged from recovery unit after achieving modified Aldrete score of 10 . The duration of stay of every patient in post anaesthesia recovery unit was noted and compared in both groups.

\section{RESULTS}

SPSS version 20 was used to analyse the data. Data was expressed as mean and standard deviation for quantitative variables and number and percentages for categorical variables. Chi square test was used to compare the two groups. $\mathrm{P}<0.05$ was considered significant. Demographic data such as age, weight and duration of surgery were comparable in both groups (Table-I). Baseline vitals such as Heart rate $(\mathrm{HR})$ and mean arterial blood pressure (MAP) were also comparable in both groups (Table-II \& III). Regarding Heart rate there was a significant decrease in heart rate in group $D$ throughout the procedure as compared to group $\mathrm{P}$ (TableII). Similarly there was a fall in MAP throughout the procedure in both groups. But when MAP was compared in both groups results were not statistically significant (Table-III). 12 out of 25 patients in group $P$ and 4 out of 25 patients in group $D$ showed respiratory depression which was evident by decrease in oxygen saturation less than $90 \%$. The recovery was much faster in group $D$ as compared to group P. The mean duration of stay in postanaesthesia recovery unit in group $D$ was $66+4$ and $80+2$ minutes in group $P$ and the difference between two groups was considered significant (Table-IV).

\begin{tabular}{|c|c|c|c|}
\hline Variable & $\begin{array}{c}\text { Group } P(n=25) \\
\text { mean } \pm S D\end{array}$ & $\begin{array}{c}\text { Group } D(n=25) \\
\text { mean } \pm S D\end{array}$ & P-Value \\
\hline Age (year) & $27.29 \pm 5.39$ & $28.71 \pm 4.12$ & 0.2964 \\
\hline Duration(min) & $12.21 \pm 4.27$ & 14.312 .79 & 0.0459 \\
\hline \multicolumn{4}{|c|}{ Table-I. Demographic data } \\
\hline
\end{tabular}

\begin{tabular}{|l|c|c|c|}
\hline \multicolumn{1}{|c|}{ Time } & $\begin{array}{c}\text { Group P(n=25) } \\
\text { mean+SD }\end{array}$ & $\begin{array}{c}\text { Group D(n=25) } \\
\text { mean } \pm \text { SD }\end{array}$ & P-Value \\
\hline 0 Mins & $85.92 \pm 11.20$ & $84.57 \pm 10.64$ & 0.6642 \\
\hline 2 Mins & $83.27 \pm 9.31$ & $73.58 \pm 8.29$ & 0.0003 \\
\hline 5 Mins & $87.31 \pm 8.43$ & $70.29 \pm 10.10$ & $<0.0001$ \\
\hline 10 Mins & $84.63 \pm 8.31$ & $69.21 \pm 7.29$ & $<0.0001$ \\
\hline 15 Mins & $85.71 \pm 10.21$ & $72.81 \pm 9.21$ & $<0.0001$ \\
\hline Post Operation & $82.37 \pm 8.47$ & $73.92 \pm 11.21$ & 0.0043 \\
\hline
\end{tabular}




\begin{tabular}{|c|c|c|c|}
\hline Time (Mins) & $\begin{array}{c}\text { Group } P(n=25) \\
\text { mean } \pm S D\end{array}$ & $\begin{array}{c}\text { Group } D(n=25) \\
\text { mean } \pm S D\end{array}$ & P-Value \\
\hline 0 Mins & $88.22 \pm 8.92$ & $86.31 \pm 9.21$ & 0.4601 \\
\hline 2 Mins & $84.31 \pm 9.21$ & $85.32 \pm 8.28$ & 0.6853 \\
\hline 5 Mins & $83.21 \pm 8.14$ & $81.32 \pm 9.27$ & 0.4475 \\
\hline 10 Mins & $79.31 \pm 10.21$ & $80.21 \pm 11.21$ & 0.7679 \\
\hline 15 Mins & $78.47 \pm 9.31$ & $80.47 \pm 8.22$ & 0.4248 \\
\hline Post Operation & $81.37 \pm 11.31$ & $82.31 \pm 10.30$ & 0.76 \\
\hline \multicolumn{4}{|c|}{ Table-III. Perioperative mean arterial blood pressure (MAP) } \\
\hline
\end{tabular}

\section{DISCUSSION}

Propofol is the most common agent used for induction of anaesthesia due to its favourable pharmakinetics. It has rapid onset and short duration of action ${ }^{8}$ It is also used as sedative for short duration procedures and for patients on mechanical ventilation. As propfol hasnoanalgesic property so it is usually used in combination with opioids such as fentanyl, nalbuphine etc in minor surgical procedures. The common adverse effects of propofol are hypotension and respiratory depression. 9,10 Dexmeditomidineis a newer drug in Pakistani market which has both sedative and analgesic properties. ${ }^{11} \mathrm{It}$ is an excellent drug used for sedation in mechanical ventilated patients. The main advantage of dexmeditomidine over propofol is that it does not cause respiratory depression and hypotension. keeping in view of these advantages we compared the hemodynamic and recovery profile of dexmeditomodine with propofol in patients undergoing dilatation and curretage. The most common minor obstetrics procedure is dilatation and curretage which is usually done as day care procedure. Tomat GS Singh et al in his study showed that although dexmeditomidine is good alternate to propofol but it is not suitable as sole sedative and analgesic agent in minor surgical procedures. ${ }^{12}$ They suggested that dexmeditomidate should be combined with opioids by using its opioid sparing property. In our study we used nalbuphine IV $0.1 \mathrm{mg} / \mathrm{kg}$ in both groups and also injection midazolam $2 \mathrm{mg}$ IV was given to patients of both groups. Similarly oxygen was given to patients of both groups at the rate of 2 liter per minute through nasal cannula.

There was a decrease in heart rate in both groups but in group $D$ decrease in heart rate was more than group P. The more pronounced decrease in heart rate might be due sympatholytic property of dexmeditomidine. The results of our study regarding heart rate were in consistent with the study of Shipra singh in which author compared the hemodynamic characteristics of dexmeditomidine plus nalbuphine vs propofol plus fentanyl in minimally invasive gynaecological procedures. ${ }^{13}$ In our study there was a decrease in mean arterial blood pressure (MAP) in both groups but when both groups were compared regarding MAP, results were insignificant. On the other hand Sethi $P$ et al. in their study found statistically significant decrease in blood pressure in propofol group when compared with dexmeditomidine group. ${ }^{14}$

P. Taniyama et al in their study showed there was no significant difference in respiratory depression between intravenous sedation with dexmedetomidine and propofol in minor oral procedures. ${ }^{15}$ But in our study the interesting finding was that the dexmedetomidine group maintained an adequate respiratory function as compared with propofol.

12 patients in group $\mathrm{P}$ showed significant decrease in oxygen saturation $(\mathrm{Spo} 2<90 \%$ ) while 4 patients in group $D$ show desaturation which was treated by increasing the flow of oxygen and head tilt chin lift maneuver.

In our study patients in dexmeditomidine group achieved discharge creteria early as compared to patients in propofol group. Modified Aldrete score was used for discharge of patients from recovery unit. Ghali, Ashraf et al. showed in their study that time to achieve an aldrete score of 10 was similar in dexmedetomidine versus propofol 
for sedation in patients undergoing vitreoretinal surgery under sub-Tenon'sanesthesia. ${ }^{16}$ On the other hand, Shah, Pratibha Jain et al. showed that the onset and recovery from propofol sedation were significantly earlier as compared to dexmeditomidine $(15.57 \pm 1.89 \mathrm{~min}$ vs. 27.06 $\pm 2.26 \mathrm{~min} ; \mathrm{P}<0.001$. $^{17}$

\section{CONCLUSION}

Dexmeditomidine is an excellent drug for day care minor surgical procedures. It produce conscious sedation and analgesia with minimal respiratory depression. It is a good alternate to propofol in short duration surgical procedures. Dexmeditomidine produce opioid sparing effects due to its analgesic properties. The recovery characteristics of dexmeditomidine is better than propofol.

Copyright@ 08 Jan, 2020.

\section{REFERENCES}

1. Tas A, Mıstanoglu V, Darcın S, Kececioglu M. Tramadol versus fentanyl during propofol-based deep sedation for uterine dilatation and curettage: A prospective study. J Obstet Gynaecol Res. 2014 Mar; 40(3):749-53.

2. Ahuja H, Abraham V, Abraham J, Liddle D. Ideal anesthetic agents for day-care gynecological procedures: A clinical trial comparing thiopentone with ketamine as adjuncts to propofol. Adv Biomed Res. 2015; 4:81.

3. Symington L, Thakore S. A review of the use of propofol for procedural sedation in the emergency department. Emerg Med J: 2006; 23(2):89-93.

4. Vijay G. Anand. Sedation in intensive care unit: Is Dexmedetomidine the best choice? IntJ CritllInInj Sci 2012 Jan-Apr; 2(1): 3-5.

5. Sudheesh K, Harsoor S S. Dexmedetomidine in anaesthesia practice: A wonder drug? Indian J Anaesth 2011; 55:323-4.

6. Subasi H, OzdemirKol I, Duger C, Kaygusuz K, Isbir AC, Gursoy S, Mimaroglu C. Dexmedetomidine and remifentanil as adjuncts to total intravenous anesthesia with propofol. Anaesth Pain \& Intensive Care $2017 ; 21(3): 328-334$
7. Kamel GF, ALIRM, Ismail AEA, Hanna BEA. Comparative evaluation of hemodynamic stability and recovery during conscious sedation by dexmedetomidine with fentanyl versus ketamine with fentanyl in dilatation and curettage. The Egyptian Journal of Hospital Medicine 2018; 73 (2), 5992- 97

8. Manjula BP, Nagaraja PS. Comparison of thiopentone sodium and propofol as anesthetic agents for modified electroconvulsive therapy. Karnataka Anaesth J 2015; 1:128-33

9. Symington L, Thakore S. A review of the use of propofol for procedural sedation in the emergency department. Emerg Med J.2006; 23(2):89-93

10. Andolfatto $\mathrm{G}^{1}$, Abu-Laban RB, Zed PJ, Staniforth SM, Stackhouse S, Moadebi S, WillmanE. Ketaminepropofol combination (ketofol) versus propofol alone for emergency department procedural sedation and analgesia: A randomized double-blind trial. Ann Emerg Med. 2012 Jun; 59(6):504-12.

11. Barends CRM, Absalom A, van Minnen B, Vissink A, Visser $A$. Dexmedetomidine versus midazolam in procedural sedation. A Systematic Review of Efficacy and Safety. PLoS ONE. 2017; 12(1):

12. Tomar GS ${ }^{1}$, Singh $\mathrm{F}^{1}$, Ganguly $\mathrm{S}$, Gaur N. Is dexmedetomidine better than propofol and fentanyl combination in minor day care procedures? A prospective randomized double-blind study. Indian Journal of Anaesthesia. 59(6):359-364.

13. Singh S, Bhamri PK. Dexmedetomidine and nalbuphine vs. propofol and fentanyl in minimally invasive gynaecological procedures: A comparative study. ejpmr, 2017,4(11), 585-589

14. Sethi P, Sindhi S, VermaA, Tulsiani KL. Dexmedetomidine versus propofol in dilatation and curettage: An openlabel pilot randomized controlled trial. Saudi Journal of Anaesthesia. 2015; 9(3):258-262

15. Taniyama K, Oda H, Okawa K, Himeno K, Shikanai K, Shibutani T. Psychosedation with dexmedetomidine hydrochloride during minor oral surgery. Anesthesia Progress. 2009; 56(3):75-80.

16. Ghali A, Mahfouz AK, Ihanamäki T, El BtarnyAM. Dexmedetomidine versus propofol for sedation in patients undergoing vitreoretinal surgery under subTenon's anesthesia. Saudi J Anaesth. 2011; 5(1).41-36

17. Shah PJ, Dubey KP, Sahare KK, Agrawal A. Intravenous dexmedetomidine versus propofol for intraoperative moderate sedation during spinal anesthesia: A comparative study. JAnaesthesiolClinPharmacol. 2016; 32(2):245-49. 


\begin{tabular}{|c|c|c|c|}
\hline \multicolumn{4}{|c|}{ AUTHORSHIP AND CONTRIBUTION DECLARATION } \\
\hline Sr. \# & Author(s) Full Name & Contribution to the paper & Author(s) Signature \\
\hline 1 & Raza Farrukh & Concept and design of study. & \\
\hline 2 & Waseem Sadiq Awan & $\begin{array}{l}\text { Data analysis \& revisiting } \\
\text { critically. }\end{array}$ & \\
\hline 3 & Ahmed Hassan Khan & Paper writing \& data analysis. & \\
\hline 4 & Asaad Rizwan Rana & $\begin{array}{l}\text { Data analysis \& revisiting } \\
\text { critically. }\end{array}$ & \\
\hline 5 & Ahmed Aziz Jilani & Data analysis. & \\
\hline 6 & Khalid Mahmood & Data analysis. & \\
\hline
\end{tabular}

